\title{
Size-associated Variation and Factors Affecting the Morphology of Brown Bodies in Glycera tridactyla (Polychaeta: Glyceridae)
}

\author{
Elif Can* \\ Dokuz Eylul University; Institute of Marine Sciences and Technology; Inciralti, Izmir - Turkey
}

\begin{abstract}
Size-associated variations in brown body morphology (size and shape) were studied from the individuals of Glycera tridactyla. Variables related to size, length $(B L)$ and width $(B W)$ of the brown bodies were measured. On the basis of these measurements, other variables such as the surface area (SA), volume (V), surface area/volume ratio (SA/V) and elongation degree (ED) were calculated. Brown body shape was quantified by the elongation degree. The immature brown bodies were significantly smaller than the mature bodies, and therefore the smaller bodies had a higher $S A / V$. Results obtained from the regression analysis showed that there was a significant relationship between all the variables with the exception of $S A / V: B W$ for the immature bodies and ED: BL for both groups of the bodies. The body size (proboscis length) of the worm and the sampling time (months) were the affecting factors on size and shape of the brown body. Brown bodies tend to be elongated as the proboscis length increased. The variation in size and/or shape of the brown bodies could refer to an adaptation to the movement along the coelomic fluid.
\end{abstract}

Key words: Bloodworm, elongation degree, encapsulation, proboscis, surface area volume ratio

\section{INTRODUCTION}

Immunity can be defined as a shield, created by the organism against external environmental effects (Dhainaut and Scaps 2001). The role of the cellular reactions is very important in the immunity defense mechanisms of invertebrates (Porchet-Henneré et al. 1987). In the defense mechanism, the foreign particles can be eliminated by encapsulation, which is one of several immune responses of an organism (Porchet-Henneré et al. 1987). The products of encapsulation are the pigmented cell aggregates consisting of more than ten coelomocytes (Valembois et al. 1992; Wieczorek-Olchawa et al. 2003). They have been described under different names such as tumors, granulama (Porchet-Henneré et al. 1987; Valembois et al. 1992), cell plates or giant multinucleate corpuscles (Blanco 2010). Recently, beside all these several terms, they are called as brown bodies (Porchet-Henneré et al. 1987; Valembois et al. 1992; Blanco 2010). These brown bodies have also been observed in Annelida. There are many studies on the immune response of Oligochaeta, but there haven't been many investigations about the defense processes of the Polychaeta (Porchet-Henneré et al. 1987).

Glycerids lack a separate blood system where the coelomic fluid takes the place of blood (Anderson 1980) contrary to the blood system of Nereis diversicolor (Porchet-Henneré et al. 1987). The brown bodies in Glycera mainly consist of amoebocytes and erythrocytes (Dhainaut and Porchet-Henneré 1988; Vetvicka and Sima 2009). In this study, morphometric measurements of natural brown bodies in Glycera tridactyla

*Author for correspondence: elif.can@deu.edu.tr 
Schmarda, 1861 were given and the possible relationships between the characteristics of brown bodies and the factors (body size of the polychaeta and time) were identified. Therefore, the primary objective of this study was to investigate the differences among the size groups of brown bodies and to establish a relationship between the size and shape of the brown bodies. The second objective was to determine if and how natural brown body morphology vary with the factors such as the body size (proboscis length) of worm or the sampling time (months).

\section{MATERIALS AND METHODS}

The specimens of $G$. tridactyla were collected monthly between January 2006 and January 2007 in Homa Lagoon (Izmir, Turkey $26^{\circ} 50^{\prime} \mathrm{N}$ $\left.38^{\circ} 53^{\prime} \mathrm{E}\right)$. The proboscis length was measured under a dissecting microscope to define the body size of the individuals before removing the brown bodies from the coelom of G.tridactyla. After the removal, brown bodies were mounted in glycerin on glass slides to examine. All the measurements of both the proboscis length and brown bodies were made using an Olympus BX50 microscope. In the present study, the brown body morphology (size and shape) are presented on the basis of the measurements (length and width) and the calculated variables derived from the length and width (surface area volume and elongation degree).
The brown bodies were assumed to have a prolate spheroid shape. A prolate spheroid has two semiaxes of the same length as the minor semi-axis (here denoted by BW/2) and the third one as the major semi-axis coincides with the minor semiaxis of the ellipse (here denoted by BL/2). In this study, six variables were identified for each brown body: body length (BL), body width (BW), volume (V), surface area (SA), surface area/volume ratio $(\mathrm{SA} / \mathrm{V})$ and elongation degree (ED). The volume and the surface area values were then calculated from the measured values (body length-width) on the assumption of the shape of the brown bodies as a prolate spheroid. The bodies were classified as immature $(\mathrm{BL}<1 \mathrm{~mm})$ and mature $(\mathrm{BL}>=1 \mathrm{~mm})$ according the size definitions described by Valembois et al. (1992).

Data were expressed as mean \pm SE with range values. The volume $(\mathrm{V})$ and surface area $(\mathrm{SA})$ of the bodies were computed using the following formula (Satterly 1960), where semi-axial lengths were defined as $a>b$ :

$$
\begin{aligned}
& V=\frac{4}{3} \pi a b^{2} \\
& S A=2 \pi\left(b^{2}+\frac{a b}{e} \sin ^{-1} e\right) ; e=\left(a^{2}-b^{2}\right) / a^{2}
\end{aligned}
$$

To quantify the brown body shape, the elongation degree $(E D=I / L)$ was used based on the formula given by Blott and Pye (2008) for sedimentary particles where " $I$ " was the minor and " $L$ " was the major axes in this paper. The shape classification was also made according to Blott and Pye (2008) (Fig. 1).
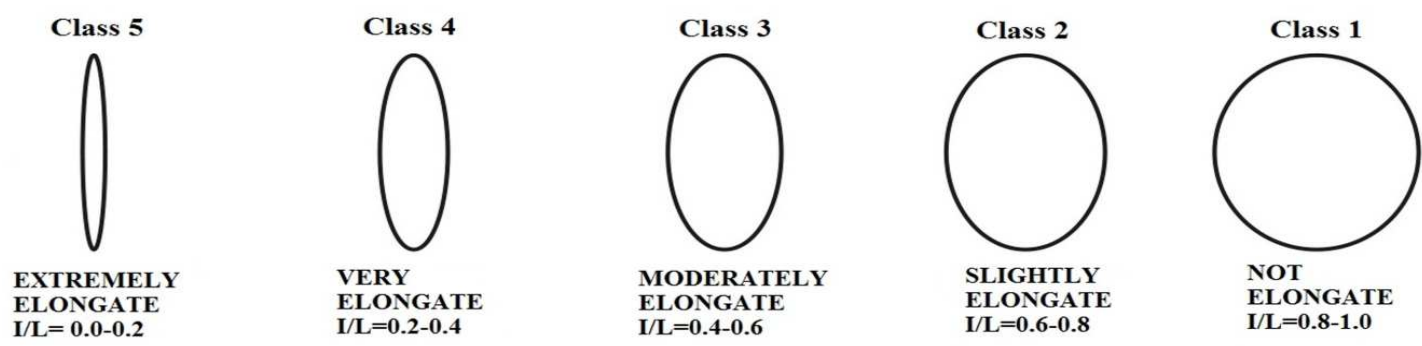

Figure 1 - The shape classification of brown bodies adapted from Blott and Pye (2008).

Student's $t$-test and $p$ values were obtained to assess the differences in the mean values of the immature and mature bodies. Linear regression analysis was performed to determine the relationship between the measured (body length width) and the calculated (the volume the surface area the surface area/volume and the elongation degree) data of brown bodies. ANCOVA was used to analyze possible factors that might affect the properties of brown bodies, including the elongation degree and surface area/volume ratio. These variables were used as dependent variables while month was defined as a fixed variable. Proboscis length was included as a covariate to 
examine if and how it influenced the brown bodies. Pearson correlation test was applied to describe the relationship between the shape characteristics of brown bodies and proboscis length measurements of $G$. tridactyla. $P$ values obtained from the statistical tests of were considered as statistically significant if the value was less than 0.05. All the statistical tests mentioned above were performed using Statistica software (Statsoft Inc. TulsaOK).

\section{RESULTS}

The mean values, standard errors and ranges for the size and shape properties and the results of the
Student's $t$-test of the 95 brown bodies are presented for both the immature and mature groups in Table 1. The mean length of the brown bodies in the immature group was significantly smaller than the mean value of the mature bodies. The same situation was also observed for the corresponding surface area and volume. On the contrary to the basic characteristics of the brown bodies, the mean value of the surface area/volume ratio of the immature brown bodies was significantly larger than the ratio of the mature ones. Brown body morphology quantified by using elongation degree showed no significant difference in mean value between immature and mature group of brown bodies.

Table 1 - The mean values standard errors and ranges for the length (BL) and the width (BW), the surface area $(\mathrm{SA})$, the volume $(\mathrm{V})$, the surface area/volume ratio $(\mathrm{SA} / \mathrm{V})$ and the elongation degree (ED) of both immature and mature brown bodies. $\mathrm{N}=$ number; $\mathrm{SE}=$ standard error.

\begin{tabular}{|c|c|c|c|c|c|c|c|c|}
\hline & \multicolumn{3}{|c|}{ IMMATURE $\quad \mathrm{N}=55$} & \multicolumn{3}{|c|}{ MATURE $\mathbf{N}=40$} & \multirow[b]{2}{*}{$\mathbf{t}$} & \multirow[b]{2}{*}{$p$ value } \\
\hline & Mean \pm SE & Min & Max & Mean \pm SE & Min & Max & & \\
\hline $\mathrm{BL} \mathrm{mm}$ & $0.69 \pm 0.03$ & 0.26 & 0.94 & $1.2 \pm 0.03$ & 1 & 1.69 & -13.25 & $<0.05$ \\
\hline $\mathrm{BW} \mathrm{mm}$ & $0.31 \pm 0.02$ & 0.10 & 0.85 & $0.47 \pm 0.03$ & 0.14 & 0.94 & -4.61 & $<0.05$ \\
\hline $\mathrm{SA} \mathrm{mm} \mathrm{m}^{2}$ & $0.60 \pm 0.06$ & 0.08 & 2.39 & $1.47 \pm 0.11$ & 0.36 & 4.00 & -7.21 & $<0.05$ \\
\hline $\mathrm{V} \mathrm{mm}^{3}$ & $0.09 \pm 0.01$ & 0.004 & 0.39 & $0.38 \pm 0.04$ & 0.08 & 1.30 & -8.48 & $<0.05$ \\
\hline $\mathrm{SA} / \mathrm{Vmm}^{-}$ & $8.05 \pm 0.44$ & 4.94 & 18.51 & $4.08 \pm 0.01$ & 2.78 & 5.56 & 7.52 & $<0.05$ \\
\hline ED & $0.47 \pm 0.03$ & 0.16 & 0.98 & $0.40 \pm 0.02$ & 0.13 & 0.84 & 1.93 & $>0.05$ \\
\hline
\end{tabular}

Linear regression lines were almost straight for the immature brown bodies showing that the surface area and the volume could be referred to as length and width dependent (Figs. 2A, 2B). The relationship between the volume, the surface area and the body width of immature bodies had high significant values $\left(\mathrm{V}: \mathrm{BW} ; R^{2}=0.7657, \mathrm{SA}: \mathrm{BW}\right.$; $\left.R^{2}=0.8794\right)$. The surface area/volume ratio showed a decreasing tendency with an increasing length $\left(\mathrm{SA} / \mathrm{V}\right.$ : $\left.\mathrm{BL} ; R^{2}=0.7863\right)$. In contrast to this relation, the surface area/volume ratio and width of immature brown bodies demonstrated a significant but rather weak relationship (SA/V: $\mathrm{BW} ; R^{2}=0.0838$ ) (Fig. 2C). The linear regression plot showed that the relationship between the elongation degree and the width was significant (ED: $\mathrm{BW} ; R^{2}=0.5432$ ) while there was no significant relationship between the elongation degree and the length of immature brown bodies (ED: $\mathrm{BL} ; R^{2}=0.0305$ ) (Fig. 2D).

The changes in the surface area and the volume of mature brown bodies with the length and width showed significant relationships (Figs. 3A, 3B).
The results revealed that the relation of the surface area, volume and width had higher regression coefficients $\left(\mathrm{V}: \mathrm{BW} ; R^{2}=0.6447, \mathrm{SA}: \mathrm{BW} ; R^{2}=\right.$ $0.9000)$ than the relation with the brown body length (V: BL; $R^{2}=0.6197, \mathrm{SA}: \mathrm{BL} ; R^{2}=0.3431$ ). Linear regression of the surface area/volume ratio to both the length and width of the bodies were also evaluated for mature bodies (Fig. 3C). The results suggested that the relationship between the surface area/volume ratio and the length $(\mathrm{SA} / \mathrm{V}$ : $\mathrm{BL} ; R^{2}=0.8796$ ) was strong but the regression line corresponding to the surface area/volume ratio and the width was nearly horizontal and the relationship was not significant $\left(\mathrm{SA} / \mathrm{V}: \mathrm{BW} ; R^{2}=\right.$ 0.0011). A strong significance was determined between the elongation degree and body width (ED: $\mathrm{BW} ; R^{2}=0.8218$ ) suggesting that the elongation degree tended to decrease with increasing brown body width. No significant relationship was observed between the elongation degree and body length of the mature brown bodies (ED: $\mathrm{BL} ; R^{2}=0.0062$ ) (Fig. 3D). 

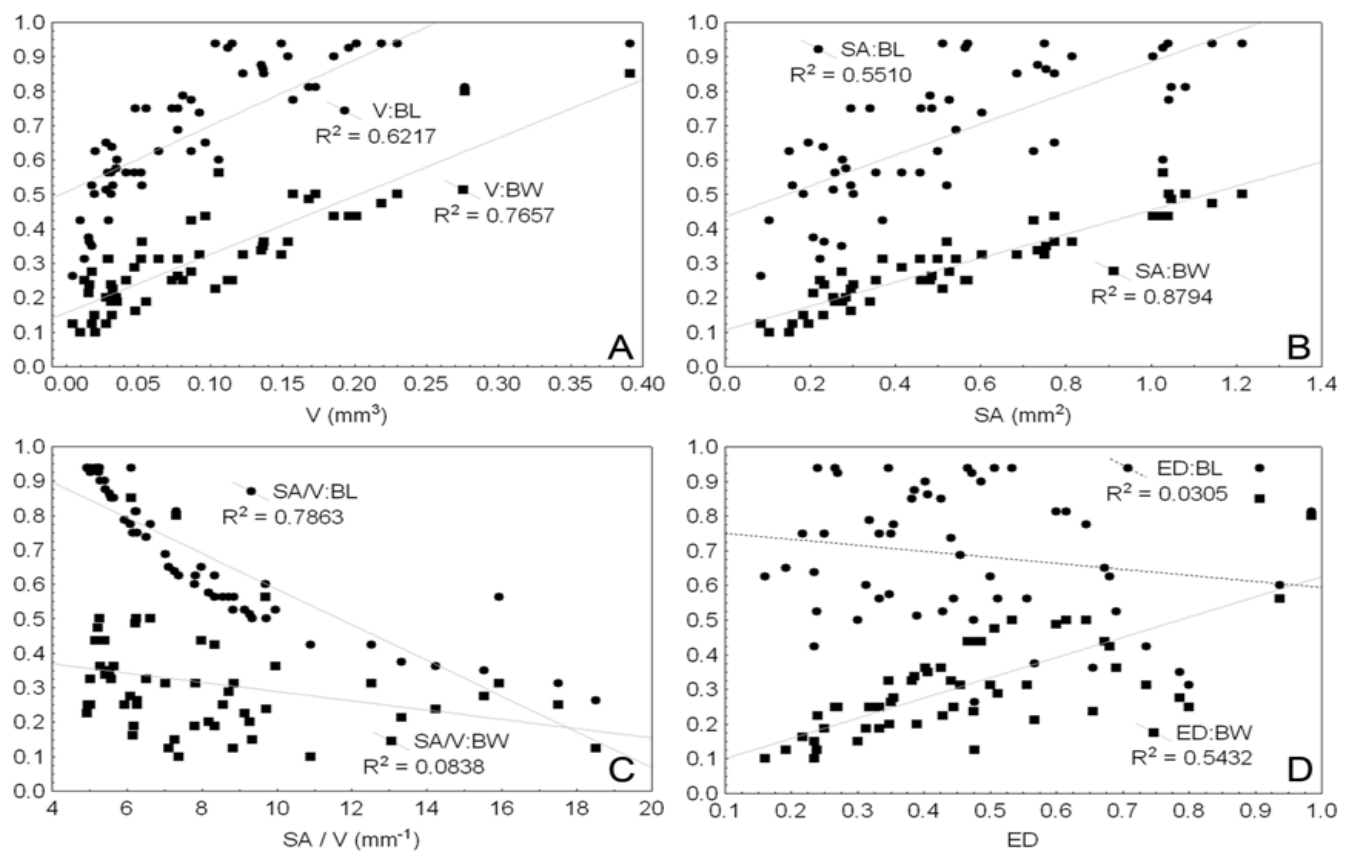

Figure 2 - Regression plots of immature brown body characteristics. y-axis denotes the BL-BW (mm) measurements. Solid lines indicate a significant linear regression $(\mathrm{p}<005)$.
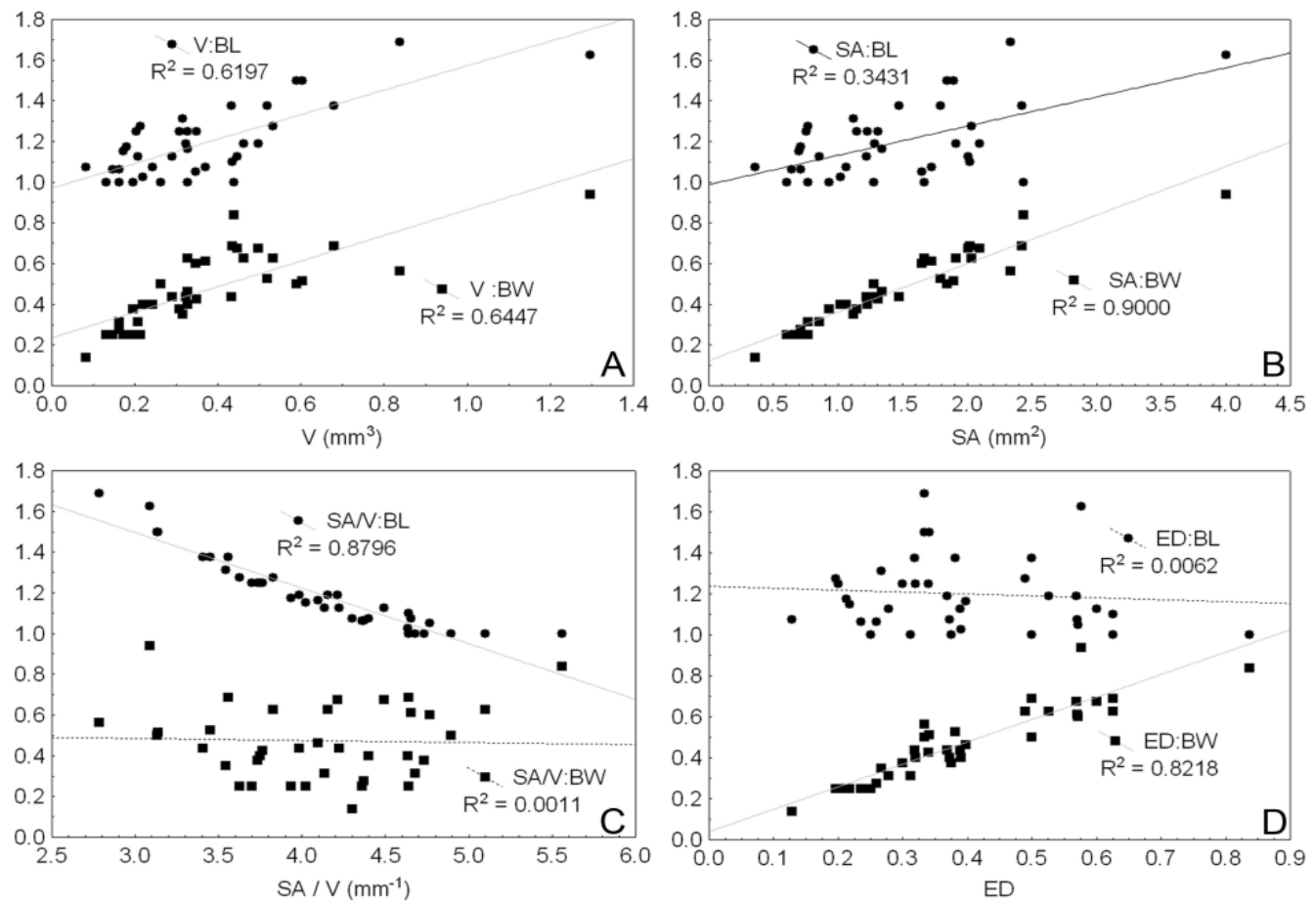

Figure 3 - Regression plots of mature brown body characteristics. y-axis denotes the BL-BW (mm) measurements. Solid lines indicate a significant linear regression $(p<005)$.

The ANCOVA results for both the surface area/volume ratio and elongation degree were not strong but significant. There were no significant interaction between the proboscis length and month, thus they were not reported in ANCOVA results. The surface area/volume ratio and proboscis length of $G$. tridactyla displayed a negative correlation, thus the individuals had long 
proboscis containing the brown bodies with a small surface area/volume ratio. There seemed to be a positive correlation between the elongation degree and proboscis length actually showing that the brown bodies tended to be elongated as the proboscis length increased. Significant differences were also noticed for the surface area/volume ratio and elongation degree among months (Table 2; Figs. 4, 5).

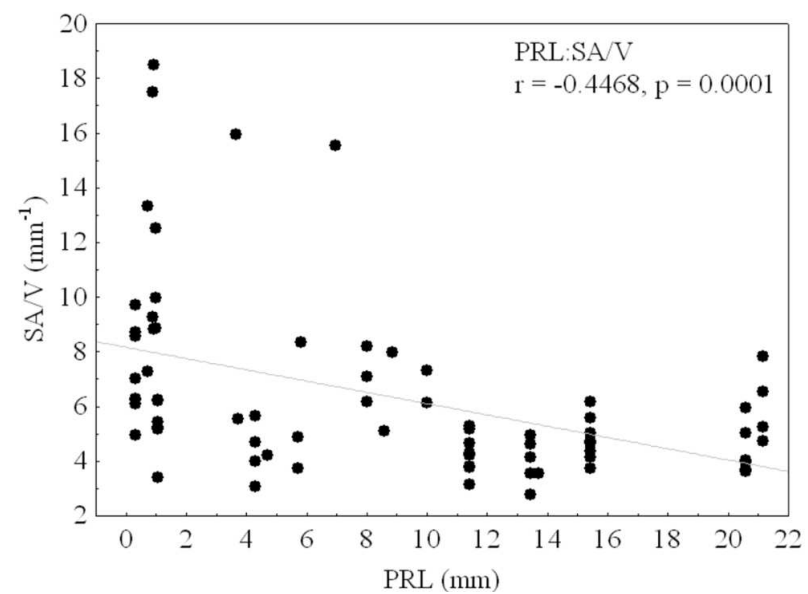

Figure 4 - Changes of the surface area/volume ratio (SA/V) of brown bodies with the proboscis length (PRL) of Glycera tridactyla.

\section{DISCUSSION}

Glycerids are subjected to a various commensals and parasites throughout their life-time (Boggemann 2002). As a consequence, brown bodies are structures associated with the defense mechanism of the host in the coelomic cavity as reported by Lunetta et al. (2004). The body surface is also used to absorb and to exchange energy and mass with the external environment to discharge a variety of metabolic products (Niklas 2000) and the smaller cells increase the surface area/volume ratio for an efficient diffusion (Young 2006). When brown bodies reach to the end of maturation level, the exchange process is reduced between the brown bodies and the other tissues of the animal (Valembois et al. 1992). This can also be a valid state for the brown bodies and the mature ones may have smaller surface area/volume ratio than immature bodies. Maturation process leads to an increase in brown body size, and thereby the surface area/volume ratio decreases. The 2/3 $(=\sim 0.667)$ ratio is the expected scaling exponent for surface area respect to body volume (Niklas 2004). As mentioned in previous studies (Kleiber
Table 2 - Results of an ANCOVA: Factors affecting the surface area/volume ratio (SA/V) and elongation degree (ED) features of brown bodies in Glycera tridactyla. $\mathrm{MS}=$ mean square; $\mathrm{DF}=$ degrees of freedom.

\begin{tabular}{lcccccccc}
\hline & \multicolumn{4}{c}{ SA/V } & \multicolumn{5}{c}{ ED } \\
\cline { 2 - 9 } & MS & DF & F & $\boldsymbol{p}$ & MS & DF & F & $\boldsymbol{p}$ \\
\hline Proboscis & 110.6 & 1 & 18.5 & $<0.05$ & 0.190 & 1 & 7.8 & $<0.05$ \\
length & & & & & & & & \\
Month & 28.6 & 9 & 4.8 & $<0.05$ & 0.097 & 9 & 4.0 & $<0.05$ \\
Error & 5.9 & 63 & & & 0.024 & 63 & & \\
\hline
\end{tabular}

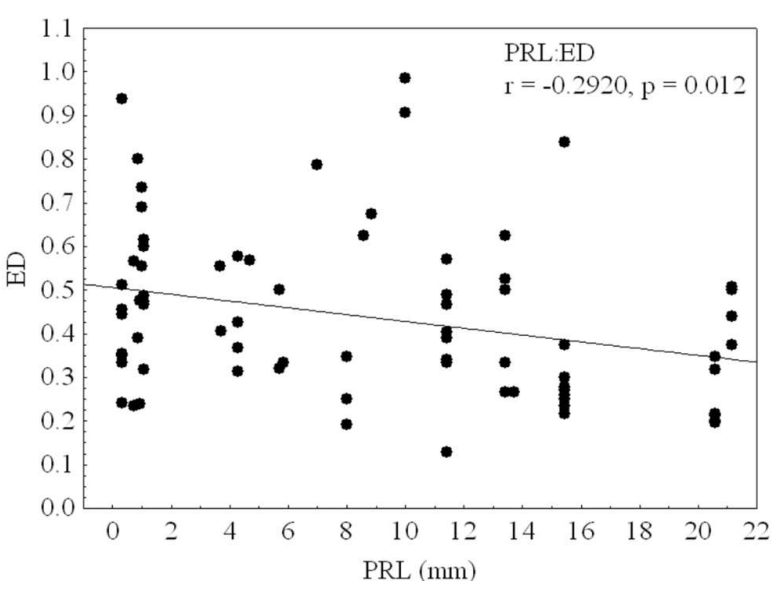

Figure 5 - Changes of the elongation degree (ED) of brown bodies with the proboscis length (PRL) of Glycera tridactyla.

1947; Paganelli et al. 1974), the surface area is proportional to $2 / 3$ power of the volume for any object differing in size but sharing the same geometry. The ratio of brown bodies did not correspond to the $2 / 3$ power rule, therefore, brown bodies were differed not only in size but also in shape. On the course of maturation, brown bodies become considerably narrower before they completely disappear (Valembois et al. 1992). The results of this study showed that as the width of brown body increased, the shapes varied from Class 5 (Extremely elongate) to the Class 2 (Slightly elongate) as a common behavior. The shape of the immature brown bodies varied from Class 2 (slightly elongate) to Class 4 (very elongate) as the shape of the mature ones from Class 3 (moderately elongate) to Class 4 (very elongate) when the width of brown body decreased. The mature brown bodies exhibited less variation in shape compared to the shape variation of immature brown bodies. The significant relation, including the surface area/volume ratio and elongation degree of brown bodies to the proboscis length of G.tridactyla specimens suggested that the worms formed larger and 
elongated brown bodies as they grew. This result was consistent when the process of brown body formation (by aggregation of coelomocytes) was considered (Valembois et al. 1992). This relation could be supported indirectly by the findings, including the dependence of the quantitative composition of coelomocytes on individual age, which was mentioned in some studies (Adamowicz and Wojtaszek 2001; Di Marzio et al. 2005). On the contrary to the findings mentioned above, Dales (1964) reported that the size of coelomocytes changed independently from the body size of an adult during the growth. The brown body formation requires generally several months (Valembois et al. 1992) and the quantity of coelomocytes varies (decreases/increases) throughout one year period due to demand of the worms in the formation process (Dales 1964). Therefore, the results of the present study were consistent with the previously mentioned views (Dales 1964; Valembois et al. 1992) that the surface area/volume ratio and elongation degree values of brown bodies changed during monthly period.

\section{CONCLUSIONS}

In conclusion, the results suggested that the variation in size and/or shape of the brown bodies might refer an adaptation in removing process in the immune defense strategy of the worm. The variation in the shape of brown bodies appeared to be changed by animal body size and time. If the brown body size variation was associated with the worm body size variation, it could be predicted that big worms would form relatively larger and elongated brown bodies than the small worms. However, this work primarily presented as an interpretation by the means of the cognitive approaches. This approach need to be confirmed with future studies on the shape of brown bodies of different species under diverse conditions to determine if the brown bodies could exhibit a generalized pattern in size and/or shape.

\section{REFERENCES}

Adamowicz A, Wojtaszek J. Morphology and phagocytotic activity of coelomocytes in Dendrobaena veneta (Lumbricidae). Zoolog Pol. 2001; 46: 91-104.

Anderson RS. Hemolysins and hemagglutinins in the coelomic fluid of a polychaete annelid Glycera dibranchiate. Biol Bull. 1980; 159: 259-268.
Blanco GA. Cell death and the immune responses of the sipunculan worm Themiste petricola. ISJ. 2010; 7: 239250.

Blott SJ, Pye K. Particle shape: a review and new methods of characterization and classification. Sedimentology. 2008; 55: 31-63.

Böggemann M. Revision of the Glyceridae Grube 1850 (Annelida Polychaeta). Abhandlungen der Senckenbergischen Naturforschenden Gesellschaft 555; 2002

Dales RP. The Coelomocytes of the Terebellid Polychaete Amphitrite johnstoni. QJMicrosc Sci. 1964; 3: 263-279.

Dhainaut A, Porchet-Henneré A. Haemocytes and coelomocytes. The Ultrastructure of Polychaeta Microfauna Marina. W Westheide, CO Hermans. Stuttgart. Gustav Fischer Verlag; 1988. p. 215-236.

Dhainaut A, Scaps P. Immune defense and biological responses induced by toxics in Annelida. Can J Zool. 2001; 79: 233-253.

Di Marzio WD, Saenz ME, Lemiere S, Vasseur P. Improved single-cell gel electrophoresis assay for detecting DNA damage in Eisenia foetida. Environ $\mathrm{Mol}$ Mutagen. 2005; 46: 246-252

Kleiber M. Body size and metabolic rate. Physiol Rev. 1947; 27: 511-541.

Lunetta GD, Farina E, Manione R. Sipunculus nudus: Particulate components of the coelomic fluid and its relationship with brown bodies. Ital J Zoology. 2004; 71: 191-199.

Niklas KJ. Plant Body Plans: Unity of type or conditions of Existence?. Gravit Space Biol Bull. 2004; 17: 133142.

Niklas KJ. The evolution of plant body plans abiomechanical perspective. Annals Bot. 2000; 85: 411438.

Paganelli CV, Olszowka A, Ar A. The avian egg: surface area volume and density. Condor. 1974; 76: 319-325.

Porchet-Henneré E, M'Beri M, Dhainaut A, Porchet M. Ultrastructural study of the encapsulation response of the polychaete annelid Nereis diversivolor. Cell Tissue Res. 1987; 248: 463-471.

Satterly J. Formulae for volumes surface areas and radii of gyration of spheres ellipsoids and spheroids. Math Gaz. 1960; 44: 15-19.

Valembois P, Lassegues M, Roch P. Formation of brown bodies in the coelomic cavity of the earthworm Eisenia fetida andrei and attendant changes in shape and adhesive capacity of constitutive cells. Dev Comp Immunol. 1992; 16: 95-101.

Vetvicka V, Sima P. Origins and functions of annelide immune cells: the concise survey. ISJ. 2009; 6:138-143.

Wieczorek-Olchawa E, Niklinska M, Miedzobrodzki J, Plytycz B. Effects of temperature and soil pollution on the presence of bacteria coelomocytes and brown bodies in coelomic fluid of Dendrobaena veneta. Pedobiologia. 2003; 47: 702-709.

Young KD. The selective value of bacterial shape. Microbiol Mol Biol Rev. 2006; 70: 660-703.

Received: November 12, 2013; Accepted: April 24, 2014. 